\title{
Uncomplicated Plasmodium vivax malaria: mapping the proteome from circulating platelets
}

\author{
Diana Fernández ${ }^{1}$, Cesar Segura' ${ }^{1}$, Mònica Arman², Suzanne McGill ${ }^{3}$, Richard Burchmore ${ }^{3}$ and \\ Tatiana Lopera-Mesa ${ }^{1 *}$ [D
}

\begin{abstract}
Background: Thrombocytopenia is frequent in Plasmodium vivax malaria but the role of platelets in pathogenesis is unknown. Our study explores the platelet (PLT) proteome from uncomplicated P. vivax patients, to fingerprint molecular pathways related to platelet function. Plasma levels of Platelet factor 4 (PF4/CXCL4) and Von Willebrand factor (VWf), as well as in vitro PLTs - P. vivax infected erythrocytes (PV-IEs) interactions were also evaluated to explore the PLT response and effect on parasite development.
\end{abstract}

Methods: A cohort of 48 patients and 25 healthy controls were enrolled. PLTs were purified from 5 patients and 5 healthy controls for Liquid Chromatography-Mass spectrometry (LC-MS/MS) analysis. Plasma levels of PF4/CXCL4 and VWf were measured in all participants. Additionally, P. vivax isolates $(n=10)$ were co-cultured with PLTs to measure PLT activation by PF4/CXCL4 and PV-IE schizonts formation by light microscopy.

Results: The proteome from uncomplicated P. vivax patients showed 26 out of 215 proteins significantly decreased. PF4/CXCL4 was significantly decreased followed by other proteins involved in platelet activation, cytoskeletal remodeling, and endothelial adhesion, including glycoprotein $\vee$ that was significantly decreased in thrombocytopenic patients. In contrast, acute phase proteins, including SERPINs and Amyloid Serum A1 were increased. High levels of VWf in plasma from patients suggested endothelial activation while PF4/CXCL4 plasma levels were similar between patients and controls. Interestingly, high levels of PF4/CXCL4 were released from PLTs—PV-IEs co-cultures while $P V$-IEs schizont formation was inhibited.

Conclusions: The PLT proteome analyzed in this study suggests that PLTs actively respond to P. vivax infection. Altogether, our findings suggest important roles of PF4/CXCL4 during uncomplicated P. vivax infection through a possible intracellular localization. Our study shows that platelets are active responders to $P$. vivax infection, inhibiting intraerythrocytic parasite development. Future studies are needed to further investigate the molecular pathways of interaction between platelet proteins found in this study and host response, which could affect parasite control as well as disease progression.

Keywords: Plasmodium vivax, Thrombocytopenia, Platelets proteome

\footnotetext{
*Correspondence: tmaria.lopera@udea.edu.co

${ }^{1}$ Malaria Group, Facultad de Medicina, Universidad de Antioquia, Calle 62 \# 52-59, Torre 1, Lab 610, Sede de Investigación Universitaria, Medellin, Colombia

Full list of author information is available at the end of the article
}

\section{Background}

Plasmodium vivax infection is widespread outside Africa [1]. South America, and specifically Colombia, are considered low endemic malaria regions where $P$. vivax accounts for $\sim 50 \%$ of malaria cases [2]. P. vivax malaria original author(s) and the source, provide a link to the Creative Commons licence, and indicate if changes were made. The images or other third party material in this article are included in the article's Creative Commons licence, unless indicated otherwise in a credit line to the material. If material is not included in the article's Creative Commons licence and your intended use is not permitted by statutory regulation or exceeds the permitted use, you will need to obtain permission directly from the copyright holder. To view a copy of this licence, visit http://creativecommons.org/licenses/by/4.0/. The Creative Commons Public Domain Dedication waiver (http://creativeco mmons.org/publicdomain/zero/1.0/) applies to the data made available in this article, unless otherwise stated in a credit line to the data. 
has been historically considered benign, mainly due to its limited replication rates in reticulocytes, that circulate at low proportion (1.5\%) in blood [3]. However, it is well known that even at lower parasitemia rates, $P$. vivax infections can lead to hemostasis dysregulation [4].

Thrombocytopenia defined as a reduced blood platelet (PLT) count, is frequent in malaria cases, and it has been described in $\sim 49 \%$ of $P$. vivax malaria patients in Colombia [5]. The causes of thrombocytopenia in P. vivax infection are unclear, but they have been related to increased PLT destruction (including the production of temporary anti-PLTs antibodies and destruction by macrophages) or higher activation/consumption [6-13], rather than decreased production. Despite the high frequency of thrombocytopenia, neither the role of PLTs in P. vivax malaria pathogenesis nor the consequences of interactions between platelets and $P$. vivax infected erythrocytes (Pv-IEs) are understood.

PLT structure, functions, and molecular activation pathways are better understood in the context of cardiovascular diseases [14]. An estimated 5000 PLT proteins, $\sim 13,600$ protein-protein interactions, and 229 PLT kinases have been described (http://plateletweb.bioapps. biozentrum.uni-wuerzburg.de/plateletweb.php) based on several proteomic approaches $[15,16]$. These studies have shed some light on the function of PLTs in hemostasis. The role of PTLs in immune response to infections has been also studied. Recently, the PLT proteome from patients with Dengue Virus, where thrombocytopenia is a hallmark, showed alterations in protein expression (e.g., PF4/CXCL4 and HLA class I proteins associated with antigen processing and presentation) [17].

PLTs have several functions including regulation of hemostasis, vascular integrity, inflammation and immune response [18]. In P. falciparum malaria, the role of PLTs has been extensively studied $[19,20]$, including their participation on IEs sequestration on the microvasculature by bridging IEs to endothelial cells (ECs) [7, 21]. Also, in vitro studies have shown direct binding between PLTs and $P$. falciparum IEs ( $P f$-IEs) forming aggregates, a phenotype known as PLT-mediated clumping [11]. Moreover, PLT activation is believed to contribute to cerebral vascular damage by inducing expression of EC adhesion molecules, leading to more PLT-endothelial interactions and cerebral vascular localization of $P f$-IEs [21, 22]. In contrast, in $P$. vivax malaria, sequestration of $P v$-IE is rare, but the imbalanced pro-inflammatory response is high compared with $P$. falciparum infections [23]. Importantly, PLT-mediated parasite killing via secretion of PF4/ CXCL4 has been described in several human-infective Plasmodium species [13, 24, 25]. However, the molecular basis of this apparent protective role of PLTs during Plasmodium infection requires further investigation.
Finally, a recent study reporting the metabolome of healthy PLTs when stimulated in vitro with $P v$-IEs showed that PLTs undergo activation. However, the PLTs directly obtained from $P$. vivax patients have not been previously studied by molecular approaches due to the frequent thrombocytopenia that makes difficult to obtain these cells. Our goal in this study was to explore the role of PLTs during uncomplicated $P$. vivax malaria episodes, through proteome analysis of PLTs from $P$. vivax patients, the evaluation of key markers of PLTs and endothelial cell activation in plasma from patients and the in vitro effect of $P v$-IEs on PLT activation as well as the effect of PLTs on parasite development.

\section{Methods}

\section{Study population}

Patients with $P$. vivax mono-infection confirmed by nested PCR, of any gender, and $>5$ years old, were enrolled in two malaria-endemic locations: Quibdo (Choco, Colombia: latitude 5.6918802, longitude - 76.6583481) and Apartado (Uraba, Colombia: latitude 7.8829899, longitude - 76.6258698). A medical evaluation including epidemiological, as well as clinical information of the patients was recorded to guarantee the absence of severity criteria, according to the regulations previously stablished in Colombia [26].

A subsample of healthy volunteers with similar age to the group of patients (Mean ten years age difference) were enrolled in this study, providing they met the following eligibility criteria: no cardiovascular or chronic disease, no chronic consumption of anti-aggregate drugs, no fever-related symptoms during the last month, no malaria diagnosis during the last two months and malaria negative during enrollment, confirmed by thick blood film, rapid diagnostic test, and nested PCR.

\section{Diagnosis of $P$. vivax mono-infection}

Detection of $P$. vivax in patients and healthy volunteers was performed by thick blood film as previously stablished [27]. Briefly, whole blood (4 mL) was collected with ethylenediaminetetraacetic acid (EDTA) to prepare thick blood films and to visualize the different stages of $P$. vivax parasites (rings, mature trophozoites, schizonts, and gametocytes) by Giemsa staining. Parasitemia was recorded using light microscopy to count the blood parasite density (parasites $/ \mu \mathrm{L}$ ). Only isolates with $>2000$ asexual parasites $/ \mu \mathrm{L}$ were used for in vitro studies as previously suggested [28].

Plasmodium vivax mono-infection was confirmed by nested polymerase chain reaction (PCR) as previously described [29]. Briefly, $200 \mu \mathrm{L}$ EDTA-whole blood were collected on filter paper (Whatman \#3) and dried at room temperature for DNA extraction, following the 
manufacturer instructions (Qiagen DNA minikit, Ref: 51,306). Plasmodium spp. genus was detected by universal PCR, using generic primers $(0.250 \mu \mathrm{M})$ rPLU1 (5'- TCA AAG ATT AAG CCA TGC AAG TGA -3') and rPLU5 (5'-CCT GTT GTT GCC TTA AAC TTC$\left.3^{\prime}\right), \mathrm{MgCl}_{2}(2 \mathrm{mM})$, dNTPs (0.2 mM per nucleotide), Taq DNA Polymerase $(2 \mathrm{U} / \mu \mathrm{L})$ and $2 \mu \mathrm{L}$ DNA. The universal PCR amplification was performed as follow: 1 cycle of $94^{\circ} \mathrm{C} \times 4 \mathrm{~min} ; 35$ cycles of $94{ }^{\circ} \mathrm{C} \times 30 \mathrm{seg}, 55^{\circ} \mathrm{C} \times 1 \mathrm{~min}$ and $72{ }^{\circ} \mathrm{C} \times 1 \mathrm{~min}$ and one cycle of final extension at $72{ }^{\circ} \mathrm{C} \times 4 \mathrm{~min}$. Then, $P$. falciparum or $P$. vivax species were detected by nested PCR using specific primers $(0.250 \mu \mathrm{M})$ rFAL1-rFAL2 (P. falciparum) and rVIV1rVIV2 (P. vivax), $\mathrm{MgCl}_{2}(2 \mathrm{mM})$, dNTPs $(0.2 \mathrm{mM}$ per nucleotide), Taq DNA Polymerase $(2 \mathrm{U} / \mu \mathrm{L})$ and $1 \mu \mathrm{L}$ of each product obtained by the universal PCR [29]. The nested PCR amplification was performed as follows: one cycle of $94^{\circ} \mathrm{C} \times 4 \mathrm{~min}$; 35 cycles of $94{ }^{\circ} \mathrm{C} \times 30 \mathrm{seg}$, $58{ }^{\circ} \mathrm{C} \times 1 \mathrm{~min}$ and $72{ }^{\circ} \mathrm{C} \times 1 \mathrm{~min}$ and one cycle of final extension at $72{ }^{\circ} \mathrm{C} \times 4 \mathrm{~min}$. The amplified products were visualized by electrophoresis (Gel Red stained).

\section{PLT proteomes from patients with uncomplicated $P$. vivax malaria}

For the PLT proteome study, a total of five patients with uncomplicated $P$. vivax malaria and five healthy controls with similar age (Mean ten years age difference) were enrolled. Whole citrated blood $(30 \mathrm{~mL})$ was collected from each participant and sent by airplane to the Malaria Reference Laboratory located in Medellín, within 4-6 h post collection to immediately extract the proteins.

PLT rich plasma (PRP) was obtained by centrifugating the whole blood at $100 \mathrm{~g} \times 20 \mathrm{~min}$. Then, PLT poor plasma (PPP) was obtained from a second centrifugation at $1200 \mathrm{~g} \times 20 \mathrm{~min}$. The PPP was frozen at $-80^{\circ} \mathrm{C}$ for further analysis (described below). To purify PLTs, the PRP was mixed with HEPES buffer (1:1) and centrifuged at $200 \mathrm{~g} \times 15 \mathrm{~min}$ to collect the supernatant. Then, PLTs were pelleted at $900 g \times 15 \mathrm{~min}$. PLTs were recovered and washed three times without suspension of the pellet, using washing buffer (sodium citrate $10 \mathrm{mM}, 150 \mathrm{mM}$ $\mathrm{NaCl}, 1 \mathrm{mM}$ EDTA, and dextrose $1 \%$ at $\mathrm{pH} 7.4$ ). All the centrifugation steps were done at room temperature to isolate PLTs from whole blood and prostaglandin $\mathrm{I}_{2}\left(\mathrm{PGI}_{2}\right.$ sodium, ref: BML-PG011-0010, Enzo life sciences) was added at $0.4 \mu \mathrm{M}$ between each centrifugation step to avoid PLT activation.

The isolated PLTs from each sample were suspended in $200 \mu \mathrm{L}$ milliQ water containing Roche's Complete ${ }^{\mathrm{TM}}$ Protease Inhibitor Cocktail $(1 \times)$. Proteins were extracted by five cycles of freezing-thawing followed by centrifugation steps at $7000 \mathrm{~g} \times 20 \mathrm{~min}\left(4^{\circ} \mathrm{C}\right)$. Total protein concentration was quantified by Bradford method and each sample was normalized to the sample with lowest protein concentration (Additional file 1: Fig. S1). The quality and integrity of extracted proteins were confirmed by 1D-electrophoresis (SDS-page) and Silver staining. The samples were stored at $-80^{\circ} \mathrm{C}$ until proteomic analysis at Glasgow Polyomics, University of Glasgow (United Kingdom).

At Glasgow Polyomics, protein samples were quantified and trypsin digested and quantified using the filteraided sample preparation (FASP) protocol, as previously described [30]. A pooled internal standard (IS) was prepared with equal amounts of peptides from patients and healthy controls to normalize the data. Then, the peptides from samples and IS were tagged using 6-plex TMT $^{\circledR}$ Mass Tagging Kit (Thermo Scientific). The LC-MS/MS was performed using an Orbitrap Elite MS (Thermo Scientific). Briefly, peptides were desalted and concentrated for $4 \mathrm{~min}$ on the trap column before being transferred to the analytical column using starting solvent conditions $(5 \%$ solvent B). A water acetonitrile gradient was used; $5-45 \% \mathrm{v} / \mathrm{v}$ solvent B from 4 to $154 \mathrm{~min}, 45-100 \%$ $\mathrm{v} / \mathrm{v}$ solvent B $154-154.1 \mathrm{~min}$, held at $100 \% \mathrm{v} / \mathrm{v}$ solvent B 154.1-160 min and then re-equilibrated at starting conditions 5\% solvent B for a total time of $165 \mathrm{~min}$. A fixed solvent flow rate of $0.3 \mu \mathrm{l} / \mathrm{min}$ was used for the analytical column. The trap column solvent flowed at a fixed $25 \mu \mathrm{l} /$ min using $1 \%$ acetonitrile with $0.05 \%$ formic acid. The Orbitrap Elite acquires a high-resolution precursor scan at $60,000 \mathrm{RP}$ (over a mass range of $\mathrm{m} / \mathrm{z} 380-1800$ ) followed by collision-induced dissociation (CID) fragmentation and detection of the top 3 precursor ions from the MS scan in the linear ion trap. The three precursor ions are also subjected to Higher-energy collisional dissociation (HCD) in the HCD collision cell, followed by detection in the orbitrap. Singly charged ions were excluded from selection, while selected precursors were added to a dynamic exclusion list for $180 \mathrm{~s}$.

Data analysis was performed using Proteome Discoverer (version 1.4), Excel 2010, and GraphPad Prism 5.0. Protein identification was performed using the Mascot search engine to interrogate the NCBI GenBank database, allowing a mass tolerance of $10 \mathrm{ppm}$ for the precursor and 0.6 Dalton for MS/MS matching. Perseus software was used for statistical paired $t$-test analysis and a volcano plot was used to depict the protein abundances between $\mathrm{Pv}$ versus $\mathrm{HC}$ groups in LC-MS/MS, through the adjusted $p$-values $\left(-\log _{10}\right)$ versus the fold change $\left(\log _{2}\right)$ obtained by $t$-test analysis. The significant differences between groups were defined by $p$-value $<0.05$ for highly confident proteins with false discovery rate $>5 \%$ (FDR), Mascot score $>100$, and coverage $>5 \%$. The protein-protein interactions were explored with confidence $>0.9$ using online database STRING (https:// 
string-db.org/) which contains the records of human protein - protein characterization and interactions at theoretical as well as experimental levels. PLT protein functions were also searched using UNIPROT (https:// www.uniprot.org) and platelet web databases (http:// plateletweb.bioapps.biozentrum.uni-wuerzburg.de/plate letweb.php).

\section{PF4/CXCL4 and VWf levels in PPP from P. vivax malaria patients}

PF4/CXCL4 levels were evaluated in PPP from each subject, using the Enzyme-linked Immunosorbent Assay (R\&D Systems DY795), following manufacturer's instructions. Additionally, VWf levels were measured in citrated plasma at the Laboratorio Clinico Hematologico (Medellin, Colombia).

\section{In vitro PLT activation by $P v$-IE parasites Preparation of PLTS}

A total of $10 \mathrm{~mL}$ of whole citrated blood was collected from healthy volunteers to obtain the PLT rich plasma (PRP) and purified PLTs as described above. Pelleted PLTs were suspended in RPMI medium (Sigma-Aldrich, R1640) without supplements and counted in Neubauer camera by light microscopy for further in vitro assays with $P v$-IEs.

\section{Collection and preparation of Pv-IEs}

Whole blood $(10 \mathrm{~mL})$ was collected in heparin from patients with $P$. vivax mono-infection, having more than 2000 parasites $/ \mu \mathrm{L}$ with $>60 \%$ of mature trophozoite stages [28, 31]. Samples were sent immediately to the Malaria Reference Laboratory for processing within 4-6 h from collection. Leukocytes were removed by centrifugation, and $P v$-IE were washed using RPMI media without serum for further in vitro assays with PLTs.

To evaluate the PLT - Pv-IE interactions in vitro, the isolated $P v$-IEs were concentrated at $50-100 \%$ parasitemia using percoll gradients at $45 \%$ as previously reported [31]. The concentrated $P v$-IEs were suspended in RPMI medium at 5\% parasitemia, and hematocrit 5\% without serum supplement. Co-culture of $P v$-IEs and PLTs $\left(2.5 \times 10^{6} \mathrm{PLT} / \mathrm{mL}\right.$ counted in Neubauer camera) were incubated $60 \mathrm{~min}$ at $37^{\circ} \mathrm{C}$ in $\mathrm{N}_{2}$ (90\%), $\mathrm{CO}_{2}(5 \%)$, $\mathrm{O}_{2}$ (5\%). Two negative controls were included: (1) $\mathrm{P} v$-IE cultured without PLTs, and (2) Uninfected erythrocytes (uEs) co-cultured with PLTs. Supernatants were collected from co-cultures and frozen at $-80{ }^{\circ} \mathrm{C}$ until analysis of PF4/CXCL4 levels by ELISA. All treatments were done in triplicate.

\section{Effect of PLTs on Pv-IE schizonts development}

To evaluate the effect of PLTs on Pv-IE schizont development, $P v$-IEs enriched with Percoll as described above, were suspended in RPMI media at parasitemia $5 \%$, hematocrit $2 \%$, and $\mathrm{AB}+$ serum $20 \%$ as previously reported [28]. Pv-IEs were stimulated with the following treatments: (1) healthy PLTs previously purified $\left(2.5 \times 10^{6} \mathrm{PLT} / \mathrm{mL}\right)$; (2) releasates of healthy PLTs $\left(2.5 \times 10^{6} \mathrm{PLT} / \mathrm{mL}\right)$ previously activated by collagen [10 $\mu \mathrm{g} / \mathrm{mL}]$; and (3) RPMI media as a control of parasite development to schizonts. All conditions were tested in triplicate.

The controls were monitored until schizont (replicating parasites $\geq$ three chromatins) formation between 20 and $24 \mathrm{~h}$. Briefly, thick blood films from growth controls and treated wells were stained with Giemsa to determine the schizont frequency (\%) by light microscopy in a total of 100 asexual parasites [28]. The frequency of gametocytes (sexual stage) was determined as a measure of parasite stress in culture. If $\geq 40 \%$ of schizonts were counted in growth controls, the isolate was considered successful for the analysis of PLT treatments. Schizont formation was compared between growth controls and treated parasites to determine the inhibition of schizont development.

\section{Results}

Clinical and epidemiological features of patients with $P$. vivax infection

A total of 48 patients with uncomplicated $P$. vivax malaria who came to the Hospital in Quibdó and Apartadó, were enrolled in this study between February-September 2018. All patients were diagnosed with $P$. vivax mono-infection by nested PCR and classified with uncomplicated $P$. vivax malaria as presented the following common symptoms: headache (79\%), chills (79\%), sweating (76\%), adynamia (71\%), myalgia (61\%), arthralgia (58\%), anorexia (58\%), sickness (50\%), low back pain (34\%) and vomiting (32\%).Twenty-six out of $48(54.2 \%)$ patients were male. Additionally, a total of 25 healthy controls who met the eligibility criteria were recruited simultaneously in the same area where patients were enrolled and 13 out of 25 (52.0\%) healthy controls were male.

General hematological parameters from patients and healthy controls, including blood PLT count, hemoglobin and hematocrit levels in both groups are shown in Table 1. As expected, thrombocytopenia (PLT count $<150.000 / \mu \mathrm{L})$ was detected in 28 out of $48(58 \%)$ patients, while all healthy controls showed normal PLT counts $(150,000-450,000 / \mu \mathrm{L})$. 
Table 1 Characteristics of uncomplicated P. vivax malaria patients and healthy controls enrolled in the study

\begin{tabular}{|c|c|c|c|c|c|}
\hline \multirow[t]{2}{*}{ Complete blood cells count } & \multicolumn{2}{|l|}{$\begin{array}{l}P^{*} \\
(n=48)\end{array}$} & \multicolumn{2}{|l|}{$\begin{array}{l}H C^{*} \\
(n=25)\end{array}$} & \multirow[t]{2}{*}{$p$-value ${ }^{a}$} \\
\hline & Median & IQR & Median & IQR & \\
\hline PLTs $10^{3} / \mu \mathrm{L}$ & 133.0 & $95.5-166.3$ & 246 & $203.0-277.5$ & $<0.0001$ \\
\hline MPV (fL) & 9.2 & $8.4-9.7$ & 9.5 & $8.55-9.6$ & 0.2753 \\
\hline PDW (Ratio) & 18.1 & $16.9-19.5$ & 16.8 & $16.2-17$ & $<0.0001$ \\
\hline PCT (\%) & 0.1 & $0.08-0.14$ & 0.218 & $0.192-0.264$ & $<0.0001$ \\
\hline Hemoglobin (g/dL) & 12.9 & $11.1-13.9$ & 13.2 & $12.05-14.5$ & 0.0972 \\
\hline Hematocrit (\%) & 38.4 & $33.5-42.3$ & 39.7 & $35.9-43$ & 0.1177 \\
\hline Age (years) & 23 & $15-41$ & 33 & $25-44$ & 0.0057 \\
\hline
\end{tabular}

*All subjects enrolled in the study include those from the proteomic cohort

IQR interquartile, MPV media PLT volume, PDW PLT distribution width, PCT plateletcrit, PV P. vivax patients. HC healthy controls

${ }^{a}$ Mann-Whitney U-test, significantly different to healthy controls $(p<0.05)$ shown in bold

\section{Changes in the PLT proteome from patients with $P$. vivax infection}

A subgroup of five uncomplicated $P$. vivax malaria patients (male: $5 / 5 ; 100 \%$ ) and five healthy volunteers (male: $3 / 5 ; 60 \%$ ) were enrolled for PLT proteome assays. The supplemental information (Additional file 2: Table S1) contains relevant information of the subgroup of patients and healthy controls collected for proteomics assays.

Through TMT-labelling approaches, a total of 215 protein entries were identified at $\mathrm{FDR}=0.05 \%$ in patients and controls, using the SwissProt Human databank. The volcano plot depicted in Fig. 1 shows the proteins abundance in Pv versus HC groups by LC-MS/MS. A total of
38 PLT proteins were found to be decreased, and five proteins were increased in patients (Fig. 1). However, only 21 decreased, and five increased proteins were selected for further analysis because of the high-quality identification, defined as Mascot score $>100$, FDR $>5 \%,>2$ peptides given match, and coverage $>5 \%$ (Table 2 ).

\section{Differentially expressed proteins in all-Pv patients}

The proteins that were upregulated or downregulated in PLT proteomes from uncomplicated $P$. vivax malaria patients are depicted in Table 2 compared to healthy controls. Decreased proteins included PF4/CXCL4 and its variant1 PF4V1/CXCL4L1, and myosins (e.g., Myosin light polypeptide 6 (MYL6), myosin regulatory light chain
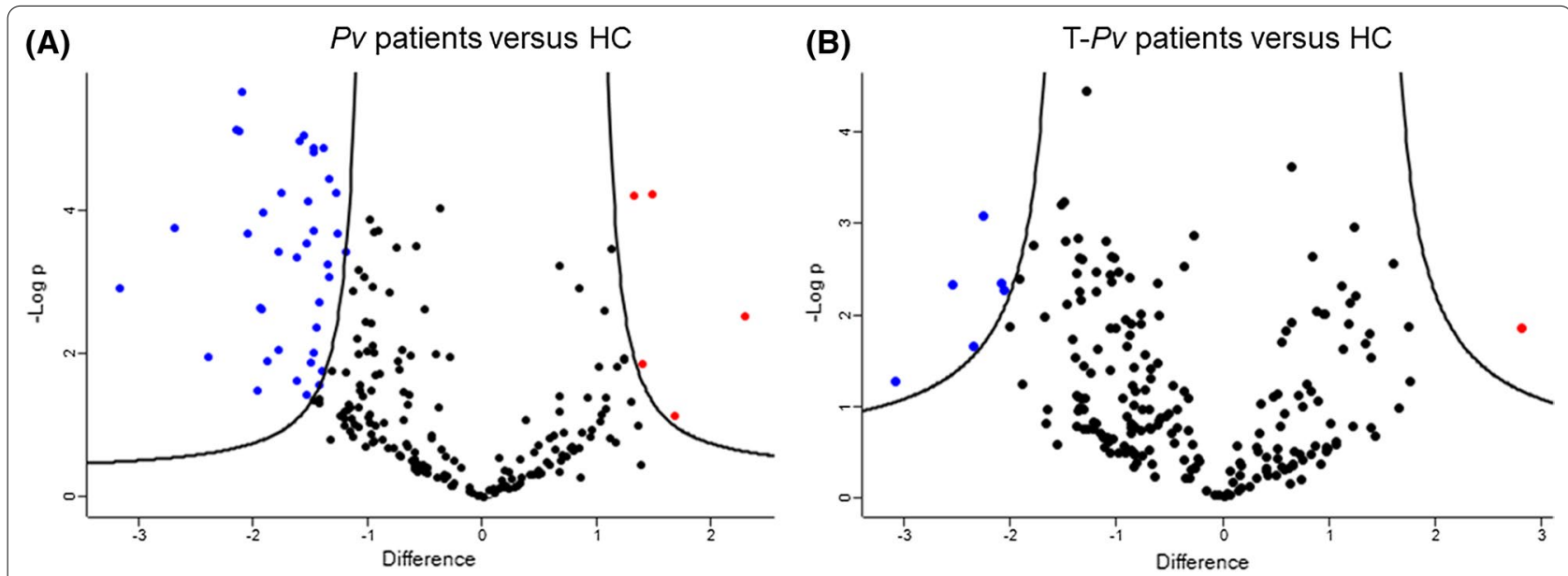

Fig. 1 Differentially expressed PLT proteomes from uncomplicated P. vivax malaria patients. Volcano plots are shown from all shared protein entries and their abundance in the following conditions: A all patients with P. vivax infection versus healthy controls by a paired $t$-test analysis; $\mathbf{B}$ patients with $<100,000 \mathrm{PLTs} / \mu \mathrm{L}$ blood (thrombocytopenia) versus healthy controls by a paired $t$-test analysis. Each dot represents a protein mapped consistently to its - Log ( $p$-value) on the ordinate axis and its difference (fold change) on the abscissa axis with FDR cutoff a (0.05). Red dots are increased proteins, blue dots are proteins decreased, and black dots are proteins equally expressed in all groups. The volcano plots were made using the Perseus Software platform 


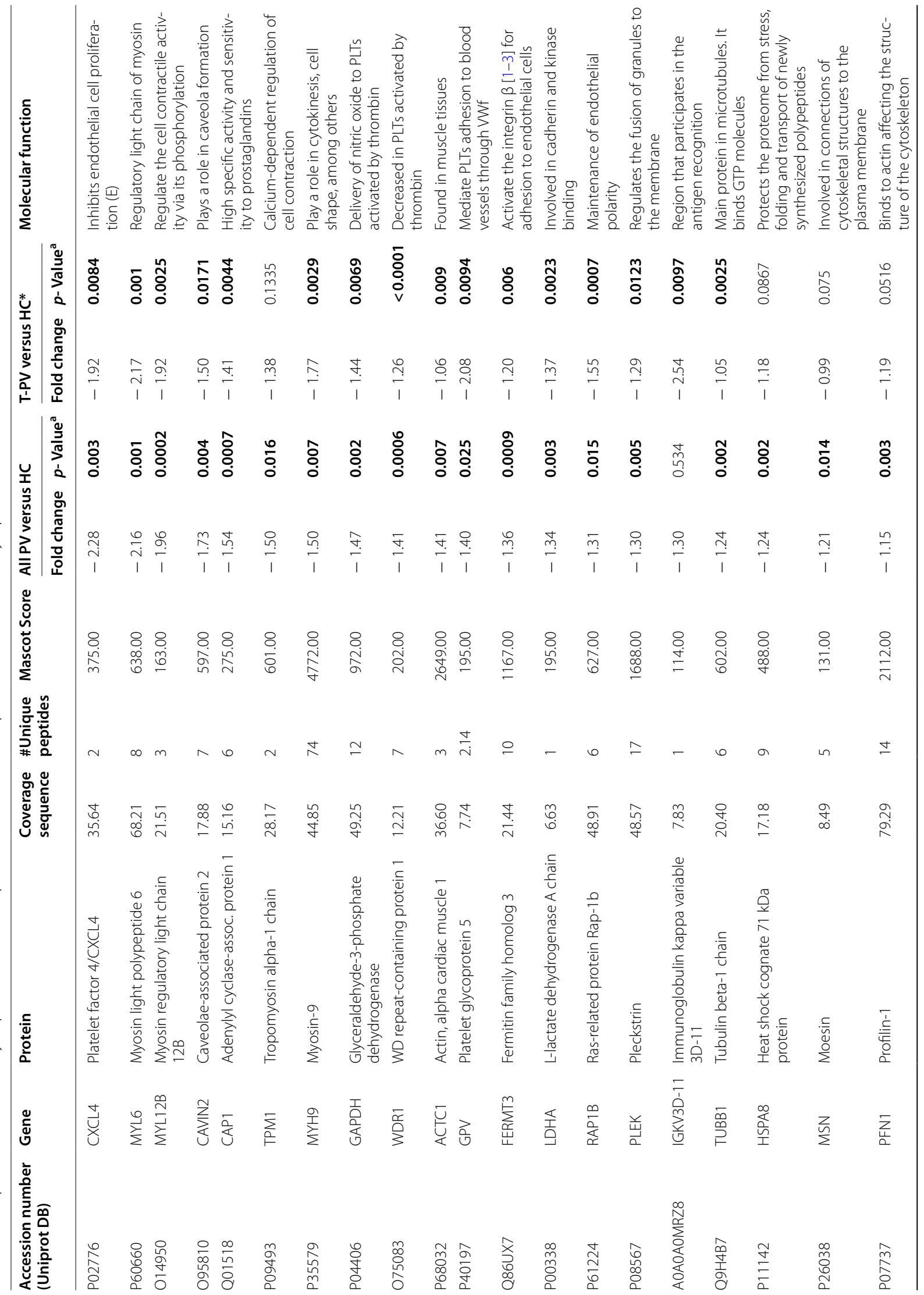




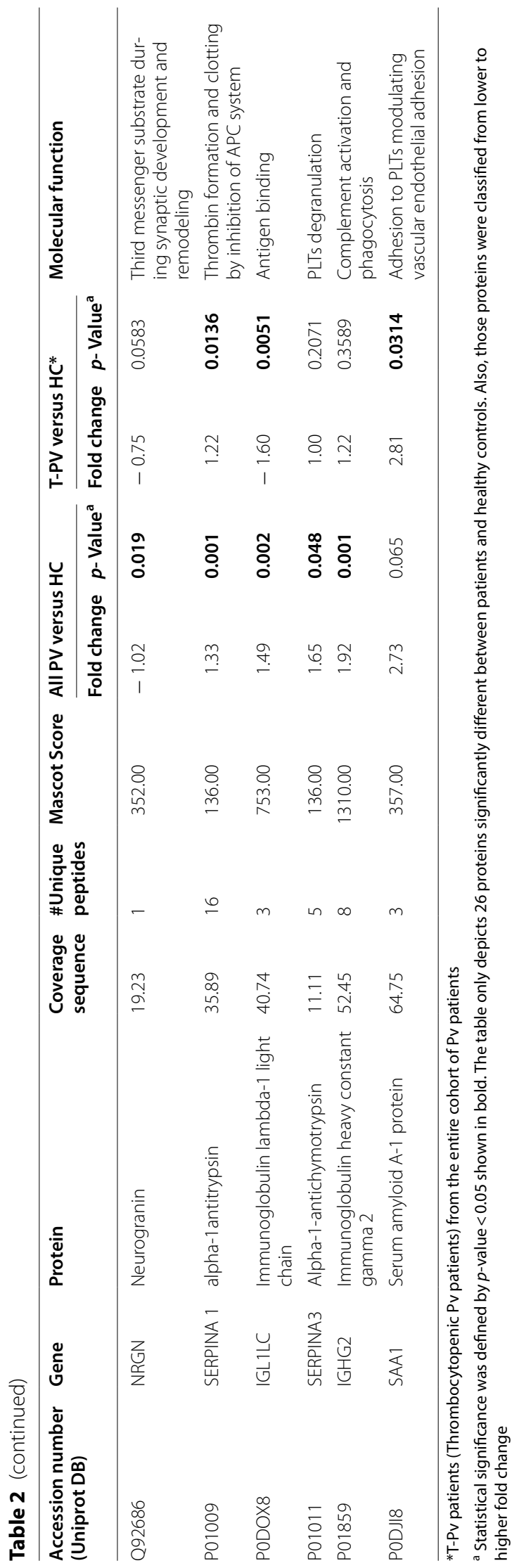


12B (MYL12B), tropomyosin alpha-1 chain (TPM1) and myosin-9 (MYH9), among others. On the other hand, the highly increased proteins included the acute phase reactants Serum Amyloid A-1 protein (SAA1), and SERPINAs 1 and 3, among others.

\section{Altered proteins in PLTs from thrombocytopenic $P$. vivax malaria patients}

As shown in Additional file 2: Table S1, three out of five PLT proteomes came from patients with thrombocytopenia (PLTs $<100,000 / \mu \mathrm{l}$ ) and the remaining 2 PLT proteomes were from patients with normal PLT count $(150,000-450,000 / \mu \mathrm{l})$. In the thrombocytopenic patients (T-Pv), a total of 3 proteins were identified as more strongly decreased compared to healthy controls. Remarkably, Glycoprotein V (GPV) and the Immunoglobulin kappa variable 3D-11 (IGKV3D-11) had twofold lower expression when compared to healthy controls (Table 2). In contrast, the PF4/CXCL4 was found to be strongly decreased in T-Pv patients compared to healthy controls while Serum Amyloid A1 (SAA1) was increased. The platelet proteomics of N-PV compared to T-PV patients did not show any statistically significant differences (data not shown), but further studies with increased patient numbers will be needed to investigate potential changes in platelets between these two groups.

\section{Biological significance of altered proteins and network of interactions}

The function(s) of the PLT proteins identified in this study were assigned based on UNIPROT and the PLT web database (http://plateletweb.bioapps.biozentrum. uni-wuerzburg.de/plateletweb.php) (Table 2). PLT expression and function of most of the identified proteins have been previously demonstrated at the experimental level. Most of these proteins have been previously found in the secretome, membrane, $\alpha$-granules, or extracellular vesicles released from PLTs. Moreover, the decreased proteins identified in our study are related to the dynamic process of PLT shape change, adhesion, and activation through calcium mobilization into the cell and maintenance of the endothelial barrier (Fig. 2, Table 2).

A network of protein-protein interactions was built with all the differentially expressed proteins using the STRING web database. We also included the protein Von Willebrand Factor (VWf) in the network due to the substantial decrease of GPV in our proteomes, since it is well known that GPV is part of a protein complex (GPIbGPIX-GPV) that interacts with VWf [41]. As shown in Fig. 2, a total of 12 interacting proteins in 15 significant edges $(p$-value $=0.0001)$ were found at a high level of confidence $(>90 \%)$, and seven interactions have previously been experimentally evidenced, mainly between myosins according to STTRING database. Further studies are needed to validate these molecular interactions during $P$. vivax infection and the progression of thrombocytopenia. Although a previous study reported that PLTs from malaria patients were highly activated [12], the relevance of PLT activation and blood coagulation in the pathophysiology of $P$. vivax malaria needs more investigation.

\section{PF4/CXCL4 and VWf levels in uncomplicated $P$. vivax infection}

To test whether the substantial decrease of PF4/CXCL4 in P. vivax PLTs could be due to PLT secretion, the plasma levels of this protein were measured. While no significant differences were detected between PV and HC groups (Fig. 3a), we found that PF4/CXCL4 plasma levels were significantly decreased in patients with low PLT count compared to patients with normal PLT count (Fig. 3b). Plasma levels of PF4/CXCL4 were not correlated with parasite density in any of these groups (data not shown: $\left.r^{2}:-0.18 ; p=0.10\right)$. In contrast, the plasma levels of VWf were increased in all- $P v$ patients compared to HC (Fig. 3a and b).

\section{In vitro effect of $P$. vivax over PLTs-PF4/CXCL4 secretion}

A total of 10 fresh $P$. vivax isolates with $>60 \%$ mature trophozoites (median of parasitemia 6800 parasites/ $\mu \mathrm{L}$; IQR: $5440-11,348)$ were used to test whether PLT activation, specifically the release of PF4/CXCL4, takes place in response to direct interaction with $P v$-IEs. PF4/CXCL4 levels were higher in supernatants of PLTs co-cultured with $P v$-IEs than those of PLTs with uninfected erythrocytes. These findings suggest that PLTs can indeed be activated and release granular content upon $P v$-IEs stimulation (Fig. 4a).

\section{In vitro effect of PLTs over $P$. vivax schizonts development}

To investigate whether entire PLTs (ePLTs) or PLT releasate compounds can impact $P$. vivax development, without the involvement of other vascular components in plasma, purified $P v$-IEs were incubated in vitro with the following treatments: (1) resting ePLTs; or (2) releasates of collagen-activated PLTs. Four out of ten (40\%) fresh $P v$-IE isolates reached $>40 \%$ of schizonts (Fig. $4 \mathrm{~b}$ ). This percentage of successful maturation agrees with our previous study and is a common finding in P. vivax cultures [42]. Despite the small sample size of successful assays in which $P v$-IEs developed to schizonts, we found a significant reduction of schizonts in Pv-IE co-cultured with ePLT and PLT releasate (Fig. 4c). Furthermore, after incubation with PLTs, characteristic features of dying $P$. vivax parasites were observed in Giemsa-stained samples, including the spread of parasite pigment (hemozoin) and pycnotic or 


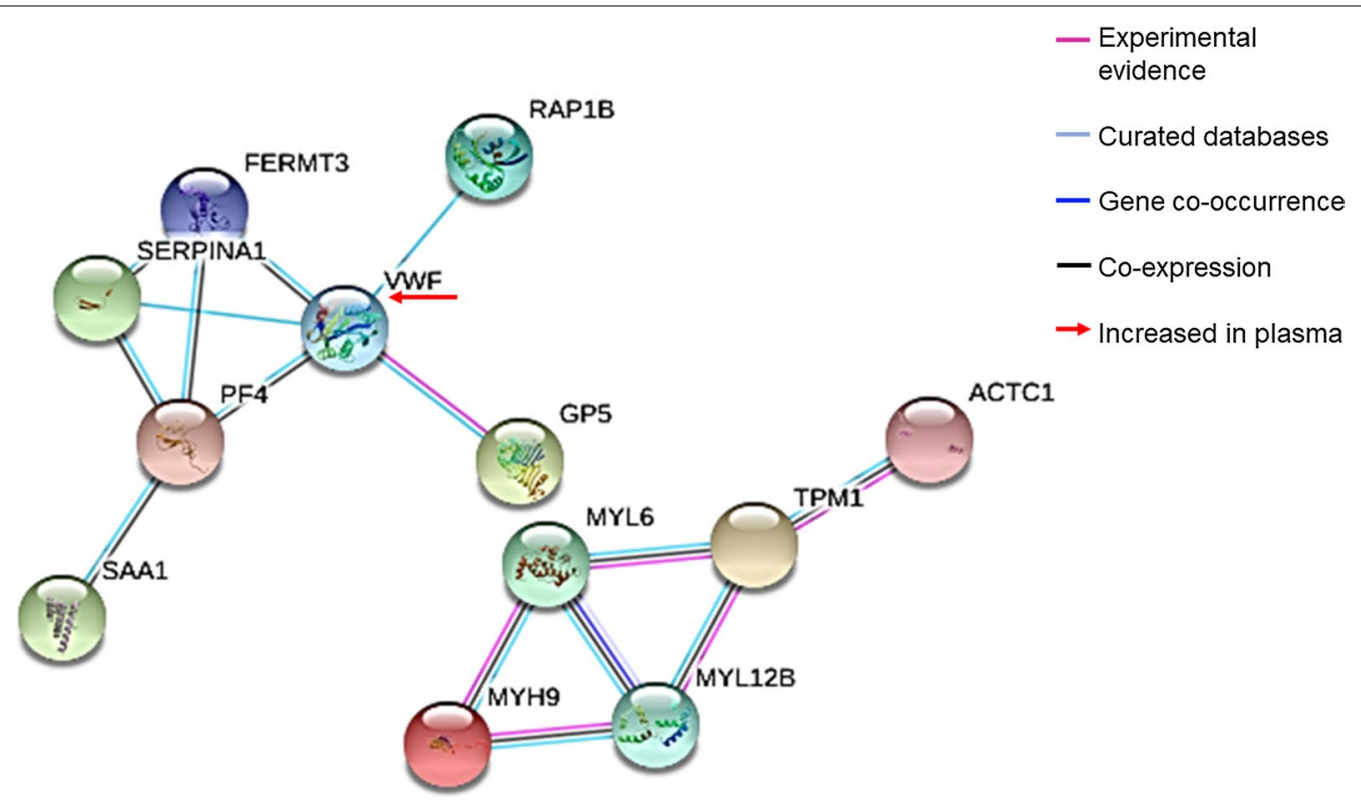

Fig. 2 Proposed model of protein interactions regulating PLTs roles in the pathogenesis of $P$. vivax infection. The figure depicts the protein-protein significant interactions found by STRING analysis ( $p$-value $<0.05$ ) with a high level of confidence (Score > 0.9). Protein names: PF4/CXCL4 (platelet factor 4); SERPINA 1 (Alpha 1 Anti-trypsin); SSA1 (serum amyloid A 1 protein); FERMT3 (Fermitin 3); TPM1 (Tropomyosin 1); ACTC1 (Actin, alpha cardiac muscle 1); MYL12B (Myosin regulatory light chain 12B); MYL6 (Myosin light chain 6); MYH9 (Myosin heavy chain 9); GP5N (Glycoprotein 5N); RAP1B; VWf (Von Willebrand Factor). The lines depict the level of interaction evidence (Purple: experimental; gray: curated databases; blue: gene co-occurrence; black: co-expression). Even though VWf was not found differentially regulated in platelet proteomes, VWf plasma levels were higher in P. vivax patients (Fig. 3), thus it was included in the interactome to analyze its relationship with the most important differentially regulated PLT proteins (Red arrow). The black arrow depicts the protein GPV significantly decreased in the T-Pv group

parasite crisis forms (Fig. 4d). Also, an increase of gametocytes was observed that could be stress-related (data not shown).

\section{Discussion}

Malaria illness is generally associated with periodic fever, chills, shivering, headache, nausea, vomiting, and many other clinical conditions [4]. In P. vivax malaria, several clinical conditions are due to the imbalance in proand anti-inflammatory cytokine production [23, 32]. In patients with acute Plasmodium vivax infection, the frequency of PLT counts under $150,000 / \mu \mathrm{L}$ can vary in different populations [33]. In this study, thrombocytopenia was present in $58 \%$ of patients, which agrees with previous reports in Colombia [5, 34].

Thrombocytopenia can be related to several variables during $P$. vivax infection, including parasitemia levels ( $>20,000$ parasites $/ \mu \mathrm{L}$ are criteria of severity) [5], as well as host variables. In this study, we did not see differences in parasitemia levels nor in host variables such as age, gender, previous malaria episodes, or clinical outcomes in relation to PLTs count. Further studies in patients with a broad spectrum of Pv-related clinical conditions will be needed to address the relationship between PLT counts, parasite load, clinical outcomes, and disease severity.
In previous studies, PLTs from $P$. vivax patients have shown impaired aggregation when in vitro stimulated with agonists but the causes are unknown [10]. Our study analyzed the PLT proteome from patients with uncomplicated $P$. vivax infection to shed light on PLT functional pathways that might be activated. Remarkably, most proteins identified here were decreased in $P$. vivax patients. Of relevance, we found PF4/CXCL4, a small chemokine $(7.8 \mathrm{kDa})$ released from $\alpha$-granules during PLT activation, and with antimicrobial properties against bacteria, viruses, and parasites [17, 25, 35]. In malaria, circulating PLTs can act as a host defense, binding directly and killing intraerythrocytic parasites of four Plasmodium species infecting humans: $P$. falciparum, $P$. vivax, $P$. malariae, and $P$. knowlesi [25].

PLTs may have dual protective and pathogenic roles during $P$. vivax infection. PF4/CXCL4 has been shown to contribute with leukocyte trafficking into the injured cerebral vasculature during experimental cerebral malaria in mice [36]. Also, clinical evidence has demonstrated that plasma PF4/CXCL4 is a predictive biomarker of cerebral malaria in humans [37], while other studies suggested this protein is not important in malaria pathogenesis $[25,38]$. Despite the decrease in PF4/CXCL4 found in our PLT proteomes from P. vivax 
(A)

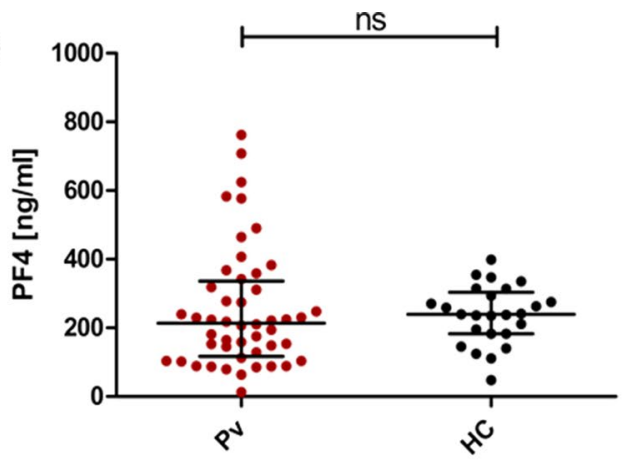

(B)

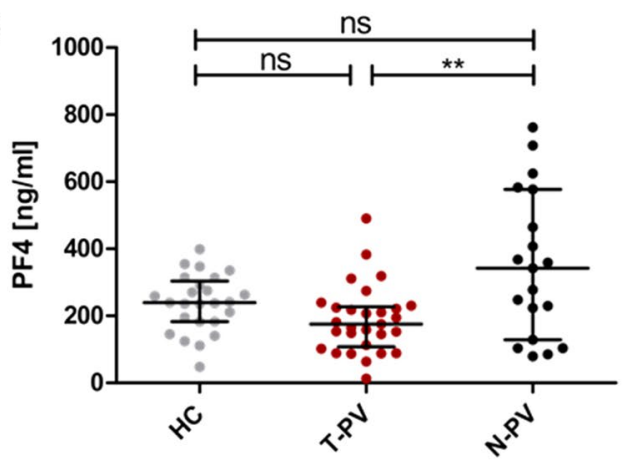

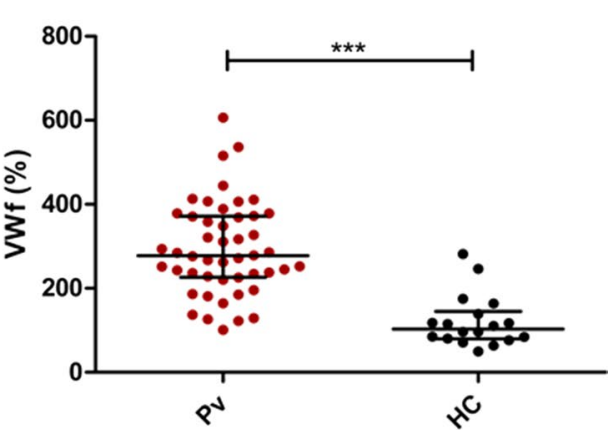

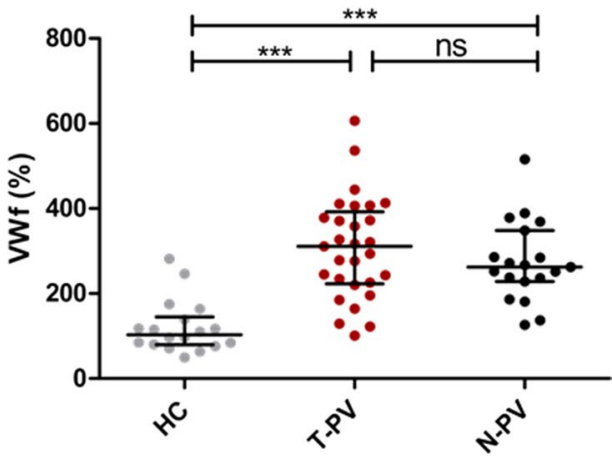

Fig. 3 PF4/CXCL4 and VWf expression in plasma from uncomplicated $P$. vivax malaria patients. A Plasma concentration of PF4 and VWf from patients with P. vivax infection (PV) and Healthy controls (HC). B Plasma concentration of PF4 and VWf in patients with normal PLTs counts (N-PV), patients with thrombocytopenia (T-PV), and healthy controls $(\mathrm{HC})$. All values are median (interquartile range) unless otherwise indicated. MannWhitney U-test, significantly different to control patients $\left({ }^{*} p<0.05 ;{ }^{* *} p<0.01 ;{ }^{* *} p<0.001\right)$

patients, we did not detect increased plasma levels of this chemokine in our patients compared to healthy donors; however, high variability was observed within the malaria group. When comparing PF4 plasma levels between N-PV and T-PV patients, the latter showed lower levels of PF4. In combination with our in vitro results, our data supports the previously proposed model in which, upon PLT-Pv-IE interaction, locally released PF4/CXCL4 traffics into the digestive vacuole of Plasmodium parasites to induce death [24, 25]. Assuming an intracellular localization of PF4/CXCL4 could be related to the normal plasma levels in most of our patients, which is in line with a previous study reporting PLT- $P v$-IE complexes and intraerythrocytic accumulation of this chemokine in uncomplicated $P$. vivax malaria patients, without detectable changes in plasma levels [25]. The higher amounts of plasma PF4/ CXCL4 detected in few of our N-PV patients might be showing the early stages of PF4/CXCL4 response to the infection. In the case of T-PV patients, albeit not significantly different from healthy controls, the lower levels of PF4/CXCL4 in plasma could be the result of the decreased number of circulating platelets combined with the local secretion and internalization of the chemokine by $P v$-IEs. Future studies will be needed to decipher the exact causes and mechanisms that lead to decreased amounts of intracellular PF4/CXCL4 cargo in platelets from PV patients; this could include not only platelet responses to IEs but also responses to other stimuli within the vasculature, and changes at the level of platelet production by megakaryocytes [39].

In $P$. vivax malaria, in vivo PLT- $P v$-IE complexes have been previously observed [25]. However, the link between those complexes, the subsequent PLT activation, and a relationship to thrombocytopenia are unclear. To measure the consequences of PLT and Pv-IE interactions, we co-cultured healthy PLTs with $P v$-IEs and showed that PLTs undergo activation releasing high levels of PF4/ CXCL4 in response to $P v$-IE stimulation. We also found that both intact PLTs and PLT releasates inhibit $P$. vivax schizonts formation causing phenotypic changes characteristic of dying parasites (namely spreading of parasite pigment suggestive of digestive vacuole dissolution). Our data agree with previous studies showing in vitro PLT killing of $P$. falciparum and P. knowlesi $[13,25,40]$. Importantly, these assays suggest that PLTs respond directly to the stimulus with $P v$-IEs without the participation of other thrombotic or inflammatory signals. 

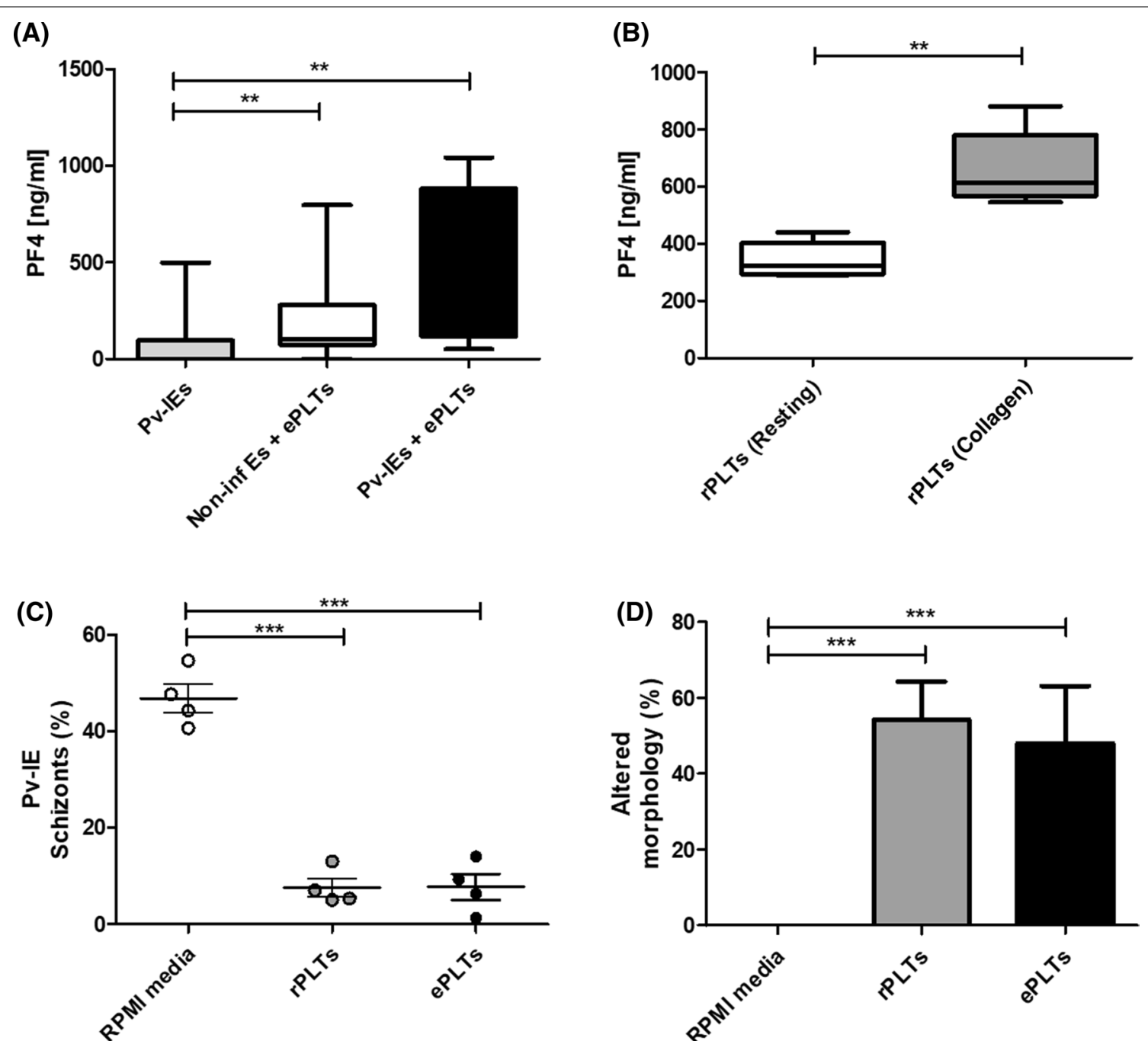

Fig. 4 Platelet activation and parasite growth inhibition in vitro. A Platelet activation by PV-IEs measured by PF4/CXCL4 release. Levels of PF4/CXCL4 from PLTs releasate (rPLTs) stimulated for $1 \mathrm{~h}$ at $37^{\circ} \mathrm{C}$ with $P v$-IE, uninfected erythrocytes (uEs), or RPMI media as a negative control. B Measurement of PF4 in PLTs releasate collected upon collagen stimulation. The rPLTs were obtained after stimulating PLTs with collagen (10 $\mu \mathrm{g} / \mathrm{mL})$ or PBS for $1 \mathrm{~h}$ at $37{ }^{\circ} \mathrm{C}$, aliquoted and stored at $-80^{\circ} \mathrm{C}$ for further in vitro assays with fresh $P$. vivax isolates (see section C). This figure shows PF4/CXCL4 levels in five collagen-stimulated sPLT aliquots thawed at different times, to test PF4/CXCL4 stability in the frozen rPLTs. PF4/CXCL4 levels from sections A and B were measured by ELISA. C Effect of PLTs and PLTs releasate on P.Vivax IE schizonts development. The figure depicts the effect of entire PLTS (ePLTs), releasate of PLTs activated by collagen $10 \mu \mathrm{g} / \mathrm{mL}$ (rPLTs), and RPMI media on PV-IE schizont formation measured after 20-24 h of co-culturing with mature trophozoites. The frequency of schizont formation (\%) was counted in Giemsa-stained thick blood films by light microscopy. D Frequency of P.vivax morphological alterations after culturing IEs with ePLTs or rPLTs. The frequency (\%) of morphologically altered parasites was recorded in $100 \mathrm{PV}$-IE. The morphological changes were defined as pycnotic nucleus, fragmented or condensed cytoplasm, and/or nucleus degradation. Kruskal-Wallis test have been shown statistical significance of mean and SD with $p$-value $*^{*}<0.05 ;{ }^{* *} p<0.01 ;{ }^{* * *} p<0.001$

Interestingly, our proteomic analysis also revealed decreased GPV in thrombocytopenic patients. This glycoprotein is a subunit of the GPIb-V-IX complex that constitutes the receptor for VWf and mediates the adhesion of PLTs to injured vascular surfaces (ref). Also, GPV can be cleaved from the surface of PLTs activated by thrombin, and ectodomain fragments of this glycoprotein may circulate in plasma, acting as potential thrombotic markers or modulators [41, 42]. We speculate that GPV may play an active role in the thrombocytopenia during uncomplicated $P$. vivax infection. However, it is currently unclear whether the decrease in GPV detected in our study is due to shedding from circulating PLTs or whether the megakaryocytes are producing PLTs with lower amounts of this glycoprotein. Our findings open questions on how the decrease in PLTs GPV relates to the 
higher levels of VWf found in plasma, and what is its relevance in the context of uncomplicated $P$. vivax malaria. Further studies are needed to elucidate the interactions between VWf and PLT receptors in $P$. vivax malaria, and the potential consequences to disease progression.

On the other hand, a few proteins were found increased in these proteomes. Serum Amyloid A 1 (SAA1) was the most upregulated protein with a 2.7 -fold change. This is an acute-phase response protein synthesized and secreted by the liver in response to inflammatory cytokines, and it can reach up to 1000-fold increase in plasma [43]. Increased plasma levels of SAA1 have been previously reported during $P$. vivax infection [44]. Additionally, a significant increase of SAA1 protein has been found in severe $P$. vivax malaria patients through proteomic studies, suggesting it could be a potential predictive marker of disease progression [44, 45]. In our study, we suggest that SAA1 was increased in the proteomes probably due to PLT uptake from the serum, since PLTs have scavenging properties [46]. Further studies are required to determine the ability of PLTs to uptake and recycle SAA1 from the extracellular environment. Two important questions are whether SAA1 removal from the circulation could slow down the transition to severe malaria and whether PLTs can secrete stored SAA1 with physiological or pathological consequences in P. vivax malaria.

An inflammatory response in our $P$. vivax patients was evidenced by the elevated plasma levels of VWf, as well as increased abundance of SAA1 in PLTs. VWf is synthetized mainly by endothelial cells (ECs) but also by megakaryocytes and it is released from ECs and PLT $\alpha$-granules upon cell activation [47]. Changes in plasma levels of VWf in malaria patients are associated with endothelial dysfunction and the risk of hemostasis dysregulation that could lead to intravascular coagulation and endothelial inflammation through increased formation of large VWf multimers and PLT aggregates [48, 49]. In this study, VWf was not found in the PLT proteomes of patients or healthy controls. We suggest this could be due to the low production of VWf from thrombopoietic cells $(\sim 15 \%$ of the total VWf $)$ while the remaining 80-90\% comes from endothelial cells [47]. The high levels of this protein found in plasma are also related to the endothelial activation previously evidenced in $P$. vivax malaria [50]. Furthermore, molecular studies are needed to fully clarify the interactions between VWf and PLTs at different stages of malaria disease.

The limitations of this study include the small sample size available for the proteomic analysis. One of the reasons was the challenge to select appropriate samples, keeping in mind that these were collected in a remote area with limited care facilities, and had to be shipped by airplane to the Malaria Reference Laboratory within 4-6 h post collection to avoid PLT activation. Another limitation of our study was the low amount of PLT proteins recovered from patient's proteomes, ranging from 0.38 and $2.69 \mu \mathrm{g} / \mu \mathrm{L}$ (Additional file 1: Fig S1). This could be due to the low PLT count in blood (Additional file 2: Table S1) and/or to some degree of protein degradation during the extraction process. However, the internal standard prepared with all samples from patients and controls was used to normalize the data due to these limitations.

More studies are required to further characterize the implications of the changes we observed in the PLT proteome, and the interaction of PLTs with VWf through GPV in the vasculature, during uncomplicated $P$. vivax infection. It is important to complement our results with proteomic analysis from patients with several clinical outcomes, validating the findings through functional assays to understand the molecular pathways orchestrating PLT functions during the infection. In this sense, some challenges include the lack of good animal models, the difficulty in establishing in vitro cultures from $P$. vivax isolates, the inability to culture PLTs from patients, and the need to establish a culture of megakaryocytes to obtain PLTs in the laboratory for further in vitro studies.

\section{Conclusions}

In summary, we show the first PLT proteome from patients with uncomplicated $P$. vivax malaria and thrombocytopenia as an effort to understand the role of PLTs in this disease. We have shown that PLT counts as well as PLT proteomes were altered in patients with uncomplicated $P$. vivax malaria. Endothelial activation takes place in uncomplicated $P$. vivax malaria as expected, which is supported by the increase of proinflammatory proteins (e.g., SAA1 in PLTs and VWf in plasma).

Interestingly, the decrease of intracellular PF4/CXCL4 and GPV suggest PLT activation and adhesion to the vascular endothelium, as well as an active role of PLTs in inhibiting schizont formation. Altogether, our findings suggest that during uncomplicated $P$. viva $x$ infection, PLTs are active players interacting with both $P v$-IEs and vascular components in the inflammatory process that takes place.

\section{Abbreviations}

PLTs: Platelets; Pv-IEs: P. vivax infected erythrocytes; Pf-IEs: P. falciparum infected erythrocytes; Pv: P. vivax; HC: Healthy controls; LC-MS: Liquid chromatographyMass Spectrometry; ECs: Endothelial cells; EDTA: Ethylenediaminetetraacetic acid; PCR: Polymerase chain reaction; DNA: Deoxyrribunucleic acid; dNTP: Deoxynucleoside triphosphate; PRP: Platelet Rich Plasma; PPP: Platelet poor plasma; FDR: False discovery rate; MPV: Media PLT volume; PDW: PLT distribution width; PCT: Plateletcrit; PF4/CXCL4: Platelet Factor 4/CXCL4; SERPINAs: Serine protease inhibitors; MYL6: Myosin light polypeptide 6; MYL12B: Myosin regulatory light chain 12B; CAVIN2: Caveolae-associated protein 2; CAP1: 
Adenylyl cyclase-assoc. protein 1; TPM1: Tropomyosin alpha-1 chain; MYH9: Myosin-9; GAPDH: Glyceraldehyde-3-phosphate dehydrogenase; WDR1: WD repeat-containing protein 1; ACTC1: Actin, alpha cardiac muscle 1; GPV: Platelet glycoprotein 5; FERMT3: Fermitin family homolog 3; LDHA: L-lactate dehydrogenase A chain; RAPB1: Ras-related protein Rap-1 b; PLEK: Pleckstrin; IGKV3D-11: Immunoglobulin kappa variable 3D-11; TUBB1: Tubulin beta-1 chain; HSPa8: Heat shock cognate 71 kDa protein; MSN: Moesin; PFN1: Profilin-1; NRGN: Neurogranin; SERPINA1: Alpha-1antitrypsin; IGL1LC: Immunoglobulin lambda-1 light chain; SERPINA3: Alpha-1-antichymotrypsin; IGHG2: Immunoglobulin heavy constant gamma 2; SAA1: Serum Amyloid A1.

\section{Supplementary Information}

The online version contains supplementary material available at https://doi. org/10.1186/s12014-021-09337-7.

Additional file 1: Figure S1. Integrity of PLT proteomes in samples. The figure depicts the band patterns detected by 1D SDS-PAGE and Silver staining in PLT protein samples from 5 patients with P. vivax infection and 5 healthy controls. MW: Molecular weight; kDa: Kilodaltons.

Additional file 2: Table S1. Main characteristics in the subgroup of patients and healthy controls enrolled for proteomic approaches

\section{Acknowledgements}

We would like to thank our patients, guardians and healthy volunteers for their participation in this study; and to the institutions located in Colombia, involved on their enrollment: Hospital Ismael Roldan Valencia; Instituto Colombiano de Medicina Tropical; and Hospital Nuestra Señora del Carmen. Many thanks to the Malaria Group for supporting the field work and sample processing; specially the Lab technicians Luisa Fernanda Carbal and Veronica Sierra who enrolled the patients. Additionally, thanks to Dr. Maria Adelaida Gomez from CIDEIM (Cali, Colombia) because of the financial support to develop the proteomic approaches. We also appreciate the support of staff at Glasgow Polyomics for processing the LC-MS/MS of PLT proteomes.

\section{Authors' contributions}

DF: Experimental design, laboratory research, data analysis, writing. CS: Experimental advisor, writing. MA: Experimental design of in vitro assays, writing. SMG: LC-MS/MS processing of samples. RB: Funding, experimental design of proteomics, writing. TL: Principal investigator, Funding, administration of the project, experimental design, writing. All authors have read and approved the final manuscript.

\section{Funding}

This study was funded by Universidad de Antioquia (Internal sources 2017); the Newton-Caldas Fund (Grant No. 172715657); and Banco de la Republica de Colombia (Grant No. 3.921).

\section{Availability of data and materials}

The MS proteomics data in this paper will be deposited in the ProteomeXchange Consortium via the PRIDE partner repository.

\section{Declarations}

\section{Ethics approval and consent to participate}

This study was performed in accordance with relevant guidelines approved by the ethics committee of the School of Medicine at Universidad de Antioquia (Communication \#002, February 2017). Patients and healthy participants voluntarily agreed to participate in this study through the approval of a written informed consent. An appropriate guardians consent, also approved by the ethics committee, was taken for patients under 18 years of age.

\section{Consent for publication}

Not applicable.

\section{Competing interests}

All authors declare that we have no significant competing financial, professional, or personal interests that might have influenced the performance or presentation of the work described in this manuscript. We are also agreed to the publishing and editorial policies of Clinical Proteomics.

\section{Author details}

${ }^{1}$ Malaria Group, Facultad de Medicina, Universidad de Antioquia, Calle 62 \# 52-59, Torre 1, Lab 610, Sede de Investigación Universitaria, Medellin, Colombia. ${ }^{2}$ Centre for Atherothrombosis and Metabolic Disease, Hull York Medical School, Faculty of Health Sciences, University of Hull, Hull, UK. ${ }^{3}$ Institute of Infection, Immunity and Inflammation and Glasgow Polyomics, College of Medical, Veterinary and Life Sciences, University of Glasgow, Glasgow, UK.

Received: 24 April 2021 Accepted: 21 December 2021

Published online: 05 January 2022

\section{References}

1. WHO. World Malaria Report 2018. World Health Organization; 2018. Contract No:: CC BY-NC-SA $3.0 \mathrm{IGO}$.

2. INS. Boletin Epidemiologico Semanal. Instituto Nacional de Salud de Colombia; 2019. Contract No.: 52.

3. Udomsangpetch R, Somsri S, Panichakul T, Chotivanich K, Sirichaisinthop J, Yang Z, et al. Short-term in vitro culture of field isolates of Plasmodium vivax using umbilical cord blood. Parasitol Int. 2007;56(1):65-9.

4. Anstey NM, Douglas NM, Poespoprodjo JR, Price RN. Plasmodium vivax: clinical spectrum, risk factors and pathogenesis. Adv Parasitol. 2012;80:151-201.

5. Arévalo-Herrera M, Lopez-Perez M, Medina L, Moreno A, Gutierrez JB, Herrera S. Clinical profile of Plasmodium falciparum and Plasmodium vivax infections in low and unstable malaria transmission settings of Colombia. Malar J. 2015;14:154.

6. Coelho HC, Lopes SC, Pimentel JP, Nogueira PA, Costa FT, Siqueira AM, et al. Thrombocytopenia in Plasmodium vivax malaria is related to platelets phagocytosis. PLoS ONE. 2013;8(5): e63410.

7. Yamaguchi S, Kubota T, Yamagishi T, Okamoto K, Izumi T, Takada M, et al. Severe thrombocytopenia suggesting immunological mechanisms in two cases of vivax malaria. Am J Hematol. 1997;56(3):183-6.

8. Ríos-Orrego AC, Carmona-Fonseca J, Blair Trujillo S. Evolución temporal de las plaquetas y los anticuerpos antiplaquetarios en pacientes de área endémica con malaria no complicada. An Med Interna. 2005;22(12):561-8.

9. Bridges DJ, Bunn J, van Mourik JA, Grau G, Preston RJ, Molyneux M, et al. Rapid activation of endothelial cells enables Plasmodium falciparum adhesion to platelet-decorated von Willebrand factor strings. Blood. 2010;115(7):1472-4.

10. Mohanty D, Marwaha N, Ghosh K, Sharma S, Garewal G, Shah S, et al. Functional and ultrastructural changes of platelets in malarial infection. Trans R Soc Trop Med Hyg. 1988;82(3):369-75.

11. Pain A, Ferguson DJ, Kai O, Urban BC, Lowe B, Marsh K, et al. Plateletmediated clumping of Plasmodium falciparum-infected erythrocytes is a common adhesive phenotype and is associated with severe malaria. Proc Natl Acad Sci USA. 2001;98(4):1805-10.

12. Aggrey AA, Srivastava $K$, Ture $S$, Field DJ, Morrell CN. Platelet induction of the acute-phase response is protective in murine experimental cerebral malaria. J Immunol. 2013;190(9):4685-91.

13. McMorran BJ, Marshall VM, de Graaf C, Drysdale KE, Shabbar M, Smyth GK, et al. Platelets kill intraerythrocytic malarial parasites and mediate survival to infection. Science. 2009;323(5915):797-800.

14. Thomas MR, Storey RF. The role of platelets in inflammation. Thromb Haemost. 2015;114(3):449-58.

15. Di Michele M, Van Geet C, Freson K. Recent advances in platelet proteomics. Expert Rev Proteomics. 2012;9(4):451-66.

16. Senzel L, Gnatenko DV, Bahou WF. The platelet proteome. Curr Opin Hematol. 2009;16(5):329-33.

17. Trugilho MRO, Hottz ED, Brunoro GVF, Teixeira-Ferreira A, Carvalho PC, Salazar GA, et al. Platelet proteome reveals novel pathways of platelet activation and platelet-mediated immunoregulation in dengue. PLOS Pathog. 2017:13(5): e1006385.

18. Andrews RK, Berndt MC. Platelet physiology and thrombosis. Thromb Res. 2004;114(5-6):447-53. 
19. Wassmer SC, Taylor TE, Rathod PK, Mishra SK, Mohanty S, Arevalo-Herrera $M$, et al. Investigating the pathogenesis of severe malaria: a multidisciplinary and cross-geographical approach. Am J Trop Med Hyg. 2015;93(3 Suppl):42-56.

20. Storm J, Craig AG. Pathogenesis of cerebral malaria-inflammation and cytoadherence. Front Cell Infect Microbiol. 2014;4:100.

21. Faille D, El-Assaad F, Alessi MC, Fusai T, Combes V, Grau GE. Plateletendothelial cell interactions in cerebral malaria: the end of a cordial understanding. Thromb Haemost. 2009;102(6):1093-102.

22. Grau GE, Mackenzie CD, Carr RA, Redard M, Pizzolato G, Allasia C, et al. Platelet accumulation in brain microvessels in fatal pediatric cerebral malaria. J Infect Dis. 2003;187(3):461-6.

23. Andrade BB, Reis-Filho A, Souza-Neto SM, Clarêncio J, Camargo LM, Barral $A$, et al. Severe Plasmodium vivax malaria exhibits marked inflammatory imbalance. Malar J. 2010;9:13.

24. Love MS, Millholland MG, Mishra S, Kulkarni S, Freeman KB, Pan W, et al. Platelet factor 4 activity against $P$. falciparum and its translation to nonpeptidic mimics as antimalarials. Cell Host Microbe. 2012;12(6):815-23.

25. Kho S, Barber BE, Johar E, Andries B, Poespoprodjo JR, Kenangalem E, et al. Platelets kill circulating parasites of all major Plasmodium species in human malaria. Blood. 2018;132(12):1332-44.

26. Tobón-Castaño A, Giraldo-Castro C, Blair S. Prognostic value of clinical and parasitological signs for severe malaria in patients from Colombia. Biomedica. 2012;32(Suppl 1):79-94.

27. Padilla J, R M. Guia de la atencion clinica de la malaria. Bogota, Colombia; 2010. Contract No.: 4.

28. Russell B, Chalfein F, Prasetyorini B, Kenangalem E, Piera K, Suwanarusk R, et al. Determinants of in vitro drug susceptibility testing of Plasmodium vivax. Antimicrob Agents Chemother. 2008;52(3):1040-5.

29. Snounou G, Zhu X, Siripoon N, Jarra W, Thaithong S, Brown KN, et al. Biased distribution of msp1 and msp2 allelic variants in Plasmodium falciparum populations in Thailand. Trans R Soc Trop Med Hyg. 1999;93(4):369-74.

30. Wiśniewski JR, Zougman A, Nagaraj N, Mann M. Universal sample preparation method for proteome analysis. Nat Methods. 2009;6(5):359-62.

31. Carvalho BO, Lopes SC, Nogueira PA, Orlandi PP, Bargieri DY, Blanco YC, et al. On the cytoadhesion of Plasmodium vivax-infected erythrocytes. J Infect Dis. 2010;202(4):638-47.

32. Gomes LT, Alves-Junior ER, Rodrigues-Jesus C, Nery AF, Gasquez-Martin TO, Fontes CJ. Angiopoietin-2 and angiopoietin-2/angiopoietin-1 ratio as indicators of potential severity of Plasmodium vivax malaria in patients with thrombocytopenia. PLoS ONE. 2014;9(10): e109246.

33. Lacerda MV, Mourão MP, Coelho HC, Santos JB. Thrombocytopenia in malaria: who cares? Mem Inst Oswaldo Cruz. 2011;106(Suppl 1):52-63.

34. Martínez-Salazar EL, Tobón-Castaño A. Platelet profile is associated with clinical complications in patients with vivax and falciparum malaria in Colombia. Rev Soc Bras Med Trop. 2014;47(3):341-9.

35. Arman M, Krauel K, Tilley DO, Weber C, Cox D, Greinacher A, et al. Amplification of bacteria-induced platelet activation is triggered by FcyRIIA, integrin allb $\beta 3$, and platelet factor 4. Blood. 2014;123(20):3166-74.

36. Morrell CN. Understanding platelets in malaria infection. Curr Opin Hematol. 2014;21(5):445-9.

37. Wilson NO, Jain V, Roberts CE, Lucchi N, Joel PK, Singh MP, et al, CXCL4 and CXCL10 predict risk of fatal cerebral malaria. Dis Markers. 2011;30(1):39-49.

38. Srivastava K, Cockburn IA, Swaim A, Thompson LE, Tripathi A, Fletcher CA, et al. Platelet factor 4 mediates inflammation in experimental cerebral malaria. Cell Host Microbe. 2008;4(2):179-87.

39. Alan D. Michelson. Platelets (Third Edition). Academic Press; 2013.

40. Peyron F, Polack B, Lamotte D, Kolodie L, Ambroise-Thomas P. Plasmodium falciparum growth inhibition by human platelets in vitro. Parasitology. 1989;99(Pt 3):317-22

41. Gardiner EE, Karunakaran D, Shen Y, Arthur JF, Andrews RK, Berndt MC. Controlled shedding of platelet glycoprotein (GP)VI and GPIb-IX-V by ADAM family metalloproteinases. J Thromb Haemost. 2007;5(7):1530-7.

42. Aleil B, Meyer N, Wolff V, Kientz D, Wiesel ML, Gachet C, et al. Plasma glycoprotein $\mathrm{V}$ levels in the general population: normal distribution, associated parameters and implications for clinical studies. Thromb Haemost. 2006;96(4):505-11.

43. Malle E, Steinmetz A, Raynes JG. Serum amyloid A (SAA): an acute phase protein and apolipoprotein. Atherosclerosis. 1993;102(2):131-46.
44. Ray S, Patel SK, Venkatesh A, Bhave A, Kumar V, Singh V, et al. Clinicopathological analysis and multipronged quantitative proteomics reveal oxidative stress and cytoskeletal proteins as possible markers for severe vivax malaria. Sci Rep. 2016;6:24557.

45. Ray S, Patel SK, Venkatesh A, Chatterjee G, Ansari NN, Gogtay NJ, et al. Quantitative proteomics analysis of Plasmodium vivax induced alterations in human serum during the acute and convalescent phases of infection. Sci Rep. 2017;7(1):4400.

46. Gaertner F, Ahmad Z, Rosenberger G, Fan S, Nicolai L, Busch B, et al. Migrating platelets are mechano-scavengers that collect and bundle bacteria. Cell. 2017;171(6):1368-82.e23.

47. Kanaji S, Fahs SA, Shi Q, Haberichter SL, Montgomery RR. Contribution of platelet vs. endothelial VWF to platelet adhesion and hemostasis. J Thromb Haemost. 2012;10(8):1646-52.

48. Swystun LL, Lillicrap D. Genetic regulation of plasma von Willebrand factor levels in health and disease. J Thromb Haemost. 2018;16(12):2375-90.

49. Saharan S, Kohli U, Lodha R, Sharma A, Bagga A. Thrombotic microangiopathy associated with Plasmodium vivax malaria. Pediatr Nephrol. 2009;24(3):623-4.

50. Dos-Santos JCK, Silva-Filho JL, Judice CC, Kayano ACAV, Aliberti J, Khouri $\mathrm{R}$, et al. Platelet disturbances correlate with endothelial cell activation in uncomplicated Plasmodium vivax malaria. PLoS Negl Trop Dis. 2020;14(7): e0007656.

\section{Publisher's Note}

Springer Nature remains neutral with regard to jurisdictional claims in published maps and institutional affiliations.
Ready to submit your research? Choose BMC and benefit from:

- fast, convenient online submission

- thorough peer review by experienced researchers in your field

- rapid publication on acceptance

- support for research data, including large and complex data types

- gold Open Access which fosters wider collaboration and increased citations

- maximum visibility for your research: over $100 \mathrm{M}$ website views per year

At BMC, research is always in progress.

Learn more biomedcentral.com/submissions 